\title{
Performance Analysis of Urban Public Transport Service Enterprise in Addis Ababa: Data Envelopment Analysis
}

\author{
Mulugeta Girma $^{1 *} \quad$ Berhanu Woldetensae ${ }^{1} \quad$ Ranavijai Bahadur Singh ${ }^{2}$ \\ 1. Ethiopian Institute of Architecture, Building Construction, and City Development, Addis Ababa University, \\ Ethiopia \\ 2.College of Urban Development and Engineering, Ethiopian Civil Service University, Ethiopia
}

\begin{abstract}
Measuring the public transit service enterprise's performance is a powerful tool for decision-making and managerial control to assess the utilization level of various inputs to obtain the desired outputs. Thus, this study aims to measure the performance of public bus transport enterprises of Addis Ababa using the Data Envelopment Analysis method during the year 2016/17 to 2017/18. There is an absence of studies in the country examining public transport sector efficiency using the DEA approach, which makes this research a chance. The study employed an input-oriented DEA model to measure bus transit efficiency. Thus, fleet size and a total number of employees are used as inputs, while covered vehicle $\mathrm{km}$ and total passengers transported per year are used as an output to measure performance. Then, the enterprises' technical efficiency and operational effectiveness are analyzed based on secondary data collected from each enterprise. The overall results show Anbessa and Sheger city buses are technically efficient and operationally effective in utilizing their inputs to deliver the desired output compared to others in the city. However, outcomes for Alliance city bus and Public Service Employees Transport Service Enterprise indicate that they utilize their inputs inefficiently and consumed their services ineffectively. Hence, these inefficient enterprises need significant improvements in using their resources to enhance their performance and deliver services incompetent with other operators in the city. Besides, the Government should encourage privately owned public transport operators in the city and provide subsidies and other incentives to all based on their existing performance.
\end{abstract}

Keywords: efficiency, public transport, Data Envelopment Analysis, Addis Ababa, Ethiopia

DOI: $10.7176 / \mathrm{PPAR} / 11-7-05$

Publication date:August $31^{\text {st }} 2021$

\section{Introduction}

The transport sector plays a substantial role in the country's overall development (Agarwal, 2016). The movement of people and goods mainly depends on transport, and it is also an expressive factor for a country to maintain a robust economy(Iles, 2005). Due to its low running and initial cost, route flexibility, and permeability into town and city centers, a conventional bus is the dominant public transport mode in most cities of developing countries (Iles, 2005; Verma \& Ramanayya, 2014). Besides, buses are the most common choice for most commuters as it is the cheapest mode of travel (Armstrong-Wright and Thiriez, 1987). Hence, the provision of adequate and proper public bus transit services is one of the most vital components for the well-being of growing and expanding urban areas (Murray et al., 1998).

However, cities in developing countries, including Addis Ababa, face a simultaneous increase in urban population, income, and private vehicle ownership, which joined with resource limitations and creates a puzzling environment for their urban transportation system(Henning et al.,2011; Norouzian-Maleki et al., 2020). Moreover, recently, a rapid increase in private vehicles set pressure on most cities of the developing world's urban transportation system. As Greene and Wegener (1997) mentioned, the growth of using personal cars aggravated the problem of congestion, traffic noise, and air pollution. Also, it harms public transport operations in the city and hurts the efficiency of transit service agencies.

Hence, in such a situation, Government should encourage people to use public transportation by designing various policies (Hafezi et al., 2013; Hwe et al., 2006). Thus, multiple governments worldwide have used various approaches to encourage changing private car users by public transit, such as buses or subways. Promoting public transport is a significant option to minimize the problems associated with urban transport in most cities in developing countries. Besides, it significantly contributes to reducing traffic congestion, air pollution, providing an alternative means of travel, and contributing highly to the worth of urban life (Estrada et al., 2020; Vuchic, 2005). Therefore, policymakers in such cities should quickly plan and implement performance-enhancing actions for their urban transport systems proportionate with the challenges they face. It requires the ability to conduct performance assessments, learn from good practice elsewhere, and recognize the areas and scale of prospective improvement (Henning et al., 2011).

The public transport system of Addis Ababa city is composed of mainly Light Rail Transit and Bus operations. The Government owns public bus operators, such as Anbessa city bus, Sheger city bus, and Public Service Employees' Transport Service Enterprise (PSETSE). The only privately owned city bus is the Alliance 
city bus. Also, the state-owned transit operators have been subsidized by Addis Ababa City Administration. For instance, in 2017/18, 52.2\% of the revenue for Anbessa city bus obtained from AACA through subsidy and $41.2 \%$ was from traffic revenue, and the remaining were from other sources. Similarly, for Sheger city bus on the same year subsidy cover, $49 \%$ of the income and $43.4 \%$ is obtained from traffic revenue (AATA, 2017/18). So, almost half of the revenue for these enterprises had covered by the city administration.

Though the Government invests a massive amount of capital in the city's public transit systems, transport is still a considerable challenge for all stakeholders. Therefore, giving significant attention to measuring and improving a transit system's performance is critical due to the severe operating environment and financial difficulties in which the sector provides service in the city. Because measuring a transit system's performance is an effective tool for ensuring the continuous improvement of service quality and allocating resources and other incentives among competing transit operators in the city.

On top of that, studies have conducted on the performance of public transport system of the city; such as Abreha, 2007; Berhan et al., 2013; Gebeyehu \& Takano, 2007a; Gebeyehu \& Takano, 2007b; Berhan, 2013 and Mihretie, 2013; however, all of them were concentrated on measuring the performance of public transport of the city emphasizing only the Anbessa bus service in the city. Also, there is a deficiency of studies in the city scrutinizing transit operators' efficiency using the DEA approach, which generates an opportunity for this research. But, some studies are conducted in the country using DEA in other sectors. To begin, Boru (2014) conducted a study on the Ethiopian banking system's efficiency using the DEA approach. The finding indicates that the bank industry's efficiency level was at a modest level. Similarly, (Dagnaw \& Wang, 2018; Garamu, 2016; Zenebe, 2017) are conducted to study the efficiency of bank sectors in Ethiopia using the DEA approach. On the other hand, (Seid, 2006) using DEA to measure the efficiency of selected hospitals in the city, and (Mutyasira, 2017) applied the DEA approach to Ethiopia's farming system.

Hence, this study would expect to fill the gap observed in the empirical literature. It also contributes to applying the DEA approach to the country's public transit system and other related sectors to measure the efficiency of organizations and identify the inefficient sectors for improvement using slack variables analysis. Therefore, this study aims to measure the enterprise's technical efficiency and operational effectiveness using the Data Envelopment Analysis model for the year 2016/17 to 2017/18.

\section{Literature Review}

\subsection{Transit Performance Measurement}

The term performance refers to any appraisal or comparison measure, and it can be considered a quantitative or qualitative characterization of performance (Eboli \& Mazzulla, 2012). Performance measurement is well-defined as assessing an organization's output as a product of the management of its internal resources (money, people, vehicles, facilities) and the environment in which it operates (Transportation Research Board, 2002). Further, it is described as the technique to evaluate how good or bad is the performance of transit service is under the prevailing operating condition (Raoniar et al., 2015).

Moreover, measuring public transit performance is an essential tool for the transport service enterprise. It generally lets them validate whether the service is delivered efficiently and effectively, to recognize areas where performance enhancement may be needed, to confirm that community and customers are satisfied; and to support decision making bodies; such as transport authorities and funding institutions, to decide where, when and how service should be provided (Henning et al.,2011). Performance measures also serve as a navigation tool that helps an organization decide where it wants to go and how to get there. It has numerous practical applications, such as trend analysis, comparisons, goal setting, system upgrading, and incentives for managers and employees. It also helps to identify potential problems and optimal solutions (Dhingra, 2011).

As Eboli \& Mazzulla (2012) measurement of transport performance embodies a very vibrant tool for confirming the continuous rise of the quality of the provided transit services, and for allotting resources among competing transport agencies. Besides, performance evaluations are an objective means of appraising performance. They are commonly thought of as one of two basic types:

i. Efficiency measures designate the association between work accomplished and the resources required to perform it.

ii. Effectiveness measures are mostly thought of as displaying how effective a transport system is concerning accomplishing its aims. Usually, this is considered with passengers carried and is measured by such factors as passengers per vehicle hour or a mile or percentage of costs recovered from operating revenues (Carotenuto et al., 2017; Carter and Lomax,1992; Dajani \& Gilbert,1978; Fielding et al.,1985; Cook and Lawrie, 2004).

Public transit performance assessments can reveal various viewpoints. Many regularly- used transit performance indicators, like load factor and cost per vehicle per $\mathrm{km}$, measure operational efficiency. Other indicators; like, rider comfort, trip speed, reliability, affordability, integration, and pleasure, reveal the user experience. User-oriented indicators are significant for developing public transit systems that account for user 
demands and invite even choice riders. It is an extent that needs thoughtful thought in most developing cities currently (Dhingra, 2011).

To sum up, as most literature on performance measurement indicates a model of transit performance forwarded by Fielding et al., (1985) used commonly to measure the performance of public transport system by defining technical efficiency as the ratio of service output (production) to inputs and operational effectiveness as the ratio of consumption to inputs as shown in the next figure 1. It shows the relationship between the three performance measures and lists the indicators related to inputs and outputs variables in the public transit system.

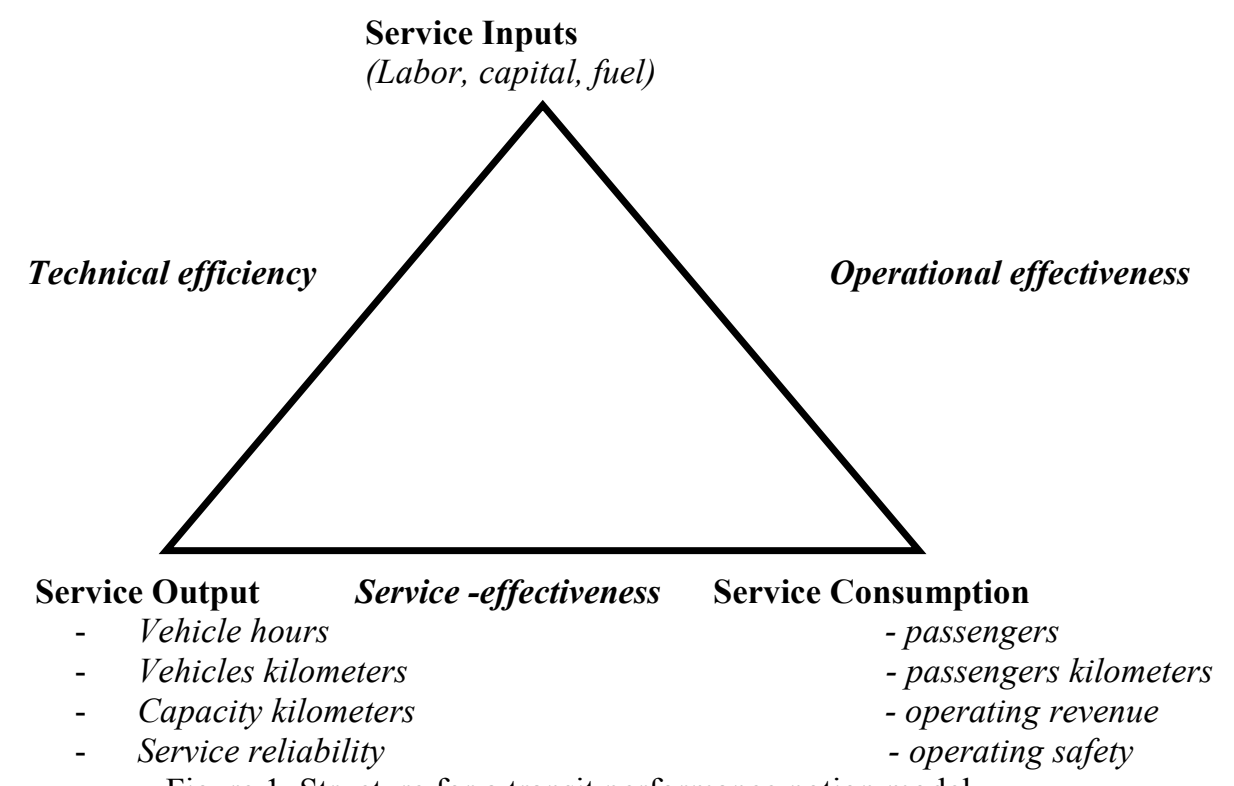

i. Technical efficiency

Figure 1. Structure for a transit performance notion model

(Source: adapted from Fielding et al., 1985; Chiou et al., 2010)

It denotes the process through which service inputs (resources) are converted into outputs. It means that a transport service provider devotes capital for vehicles, fuel, workforces, and other resources and produces a specific yield for the public, such as vehicle $\mathrm{km}$, seat $-\mathrm{km}$, and service hours. Therefore, an operator is considered efficient if it can decrease inputs to produce a fixed amount of outputs or maximize output while using the same or fewer inputs.

ii. Operational effectiveness

It shows the connection between service inputs (resources) and consumed service. Thus, a transit operator spends capital to deliver its service; several passengers consume its service per day/month/year. Hence, an Operator will achieve higher operational or cost-effectiveness, if it enhances the number of passengers without increasing the total cost of generating the service.

iii. Service effectiveness

It measures the relationship between produced output and consumed service or shows how well the community consumes the delivered services by operators. This is because all of the delivered services (i.e. vehicle $-\mathrm{km}$, seat$\mathrm{km}$, etc.) are not used by a community. Hence, if it attracts more users without enhancing services or minimizes service but still serves the same number of passengers, it will be more effective.

Therefore, this study's main emphasis is also to evaluate the performance of public bus transit operators in Addis Ababa city based on the Transit Performance Concepts Model forwarded by Fielding et al.,( 1985).

\subsection{Previous Studies}

DEA is one of the powerful techniques used for measuring the performance of various DMUs that consume multiple inputs to generate various outputs. And, it has been widely used to measure the performance of public transport systems. For instance; Kral and Rohacova, 2013; Han and Hayasn, 2008 are employed the DEA model to measure the mass transit system's efficiency and identify the efficient and inefficient DMUs in their studies. Besides, Barnum et al., (2007) also applied DEA in measuring the park's efficiency and ride a lot in public transport systems using DEA. Some studies that used DEA are summarized as follows with input and output variables used for their research. 
Table 1. Studies Applying DEA in the public transit system

\begin{tabular}{|c|c|c|c|c|}
\hline Author(s) & DMUs & Inputs & Outputs & DEA Model \\
\hline $\begin{array}{l}\text { Kral, P. and } \\
\text { Rohacova, } V . \\
(2013)\end{array}$ & $\begin{array}{l}20 \text { Transport } \\
\text { companies }\end{array}$ & $\begin{array}{l}\text { the average number of employees, } \\
\text { total } \mathrm{km} \text { driven, the total number of } \\
\text { vehicles, tangible fixed asset, and } \\
\text { operation cost }\end{array}$ & $\begin{array}{l}\text { total number of } \\
\text { passengers, } \\
\text { sales }\end{array}$ & $V R S-D E A$ \\
\hline Ayadi (2013) & $\begin{array}{l}12 \quad \text { urban } \\
\text { transit system } \\
\text { in Tunisia }\end{array}$ & $\begin{array}{l}\text { total number of bus park, number of } \\
\text { staff, fuel consumed }\end{array}$ & traveled $\mathrm{km}$ & $\begin{array}{l}\text { DEA } \\
\text { Regression } \\
\text { model }\end{array}$ \\
\hline $\begin{array}{l}\text { Lao, } \\
(2009)\end{array}$ & $\begin{array}{l}24 \text { fixed routes } \\
\text { in Monterey } \\
\text { country, USA }\end{array}$ & $\begin{array}{l}\text { operation time, round trip distance, } \\
\text { number of bus stops, persons with } \\
\text { disabilities, and commuter } 65 \text { and } \\
\text { above }\end{array}$ & $\begin{array}{l}\text { total number } \\
\text { passenger }\end{array}$ & $D E A$ \\
\hline $\begin{array}{l}\text { Han and } \\
\text { Hayasn(2008) }\end{array}$ & $\begin{array}{l}652 \\
\text { Urban } \\
\text { transport } \\
\text { system }\end{array}$ & $\begin{array}{l}\text { number of employees, number of } \\
\text { vehicles, energy consumption }\end{array}$ & $\begin{array}{l}\text { number } \\
\text { passengers }\end{array}$ & $D E A$ \\
\hline $\begin{array}{l}\text { Barnvma, et. } \\
\text { al. (2007) }\end{array}$ & $\begin{array}{l}16 \text { park and } \\
\text { ride lot }\end{array}$ & $\begin{array}{l}\text { number of parking spaces, } \\
\text { operating cost }\end{array}$ & $\begin{array}{l}\text { number of the parked } \\
\text { car, revenue }\end{array}$ & $\begin{array}{l}D E A \\
S F A\end{array}$ \\
\hline
\end{tabular}

\section{Materials and Method}

\subsection{Materials}

For the study, annual reports were collected from Anbessa city bus, Sheger city bus, Alliance city bus, and PSETSE bus for the year 2016/17 and 2017/18.

\subsection{Method}

Data envelopment analysis (DEA) is a technique for evaluating the relative efficiency of Decision-Making Units (DMUs) that produce similar products (Charnes, Cooper, and Rhodes 1978; Azadeh, Salehi, \& Kianpour, 2018; Norouzian-Maleki et al., 2020). It is also a relatively new "data-oriented "method for assessing the performance of a set of peer entities or DMUs, which change multiple inputs into multiple outputs( Cooper, Seiford, and Zhu,2011).

The DEA frontier is non-parametric; no functional formulation wants to be stated, and each input/output variable can be measured in its usual measurement units; such as the hectare, meters, or numbers (Almawsheki \& Shah, 2015).

DEA has been practiced in many sectors, such as Banks, hospitals, education, health care, finance, utilities, and Agricultural sectors. Also, DEA has been applied in Transport sectors like ports, railways, airlines, urban transit, airports, etc. So, DEA determines each transit enterprise's efficiency within a group relative to other operators in the group.

The most basic DEA model is the CCR model that Charnes, Cooper, and Rhodes proposed in 1978. It was developed to assess the relative efficiency of homogeneous DMUs with multiple inputs and multiple outputs. Also, the DEA-CCR model is used because it states the overall technical efficiency of each DMU (Almawsheki \& Shah, 2015).

The CCR model is considered the most popular DEA technique, which assumes that there are $n$ DMUs that each use $\mathrm{m}$ inputs to produce $\mathrm{s}$ output(s) (Banker, Charnes, and Cooper 1984). The CCR model measures the DMU's relative efficiency by comparison to a group of other DMUs that use the same input(s) and output(s). The CCR model is expressed as follows: 


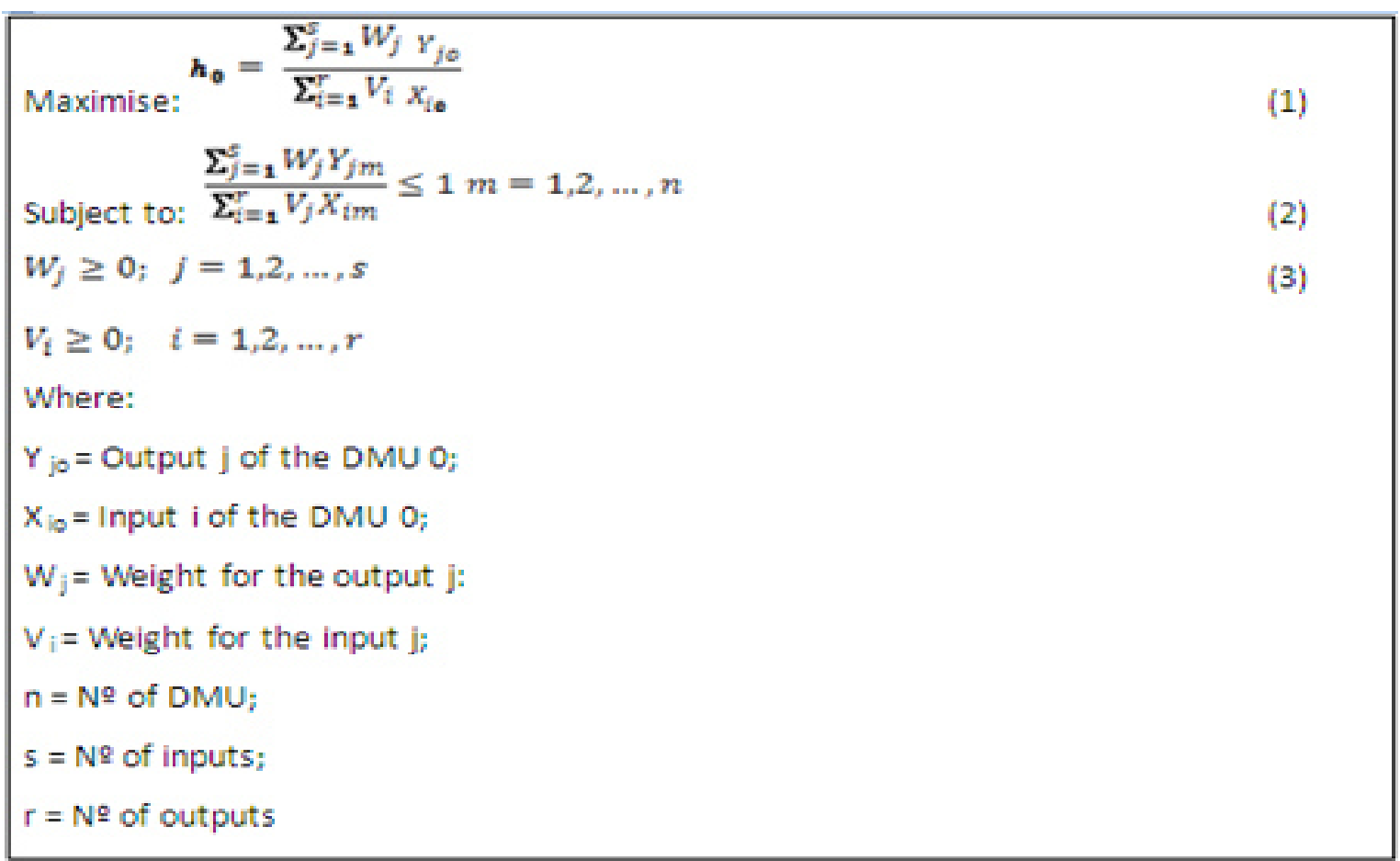

If $\mathrm{h}_{\mathrm{o}}=1$, it means that DMU $\mathrm{o}_{\mathrm{o}}$ is efficient relative to other similar DMUs. If $\mathrm{h}_{\mathrm{o}}<1$, then the DMU $\mathrm{o}_{\mathrm{o}}$ is inefficient. Therefore, for this study the DEA-CCR input orientation model is employed and the step-wise procedure used is described as follows;

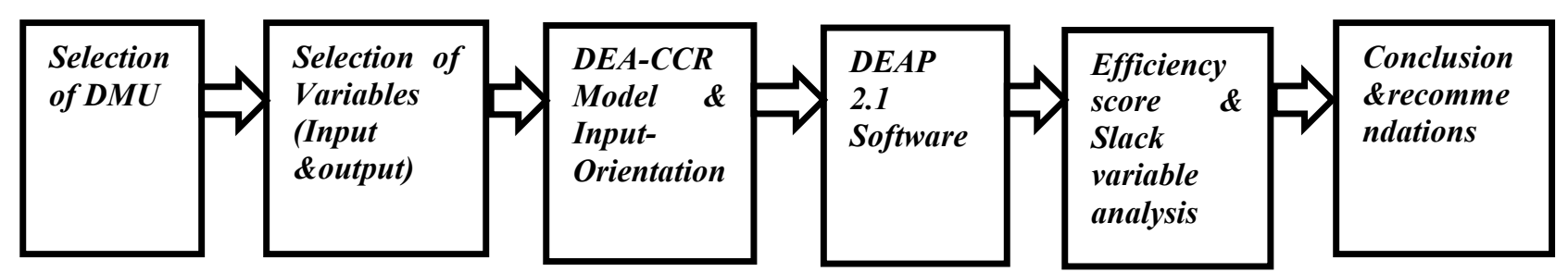

Figure 2. Research Procedure of the study

Thus, as shown above, DMUs were first selected (i.e. Anbessa, Sheger, PSETSE, and Alliance city bus enterprise) were included for the study. Regarding the number of DMUs, the study was supported by a rule of thumb; i.e. Dyson, et. al. (2001) suggest that if there are $\mathrm{M}$ inputs and $\mathrm{N}$ outputs, there need to be at least $2 \mathrm{M}^{*} \mathrm{~N}$ DMUs in the set to be compared. So, there are two inputs and one output, and four DMUs ( $n \geq 2 * 2 * 1)$ for this study.

The selection of input and output variables is a significant part of evaluating the efficiency of the enterprise. So, based on the objective and mission of the transit agencies, literature review on input and output factors used in other studies, and availability of data the following variables are used as inputs and output in this study: Input variables (number of employees and number operated buses), output variable (total covered $\mathrm{km}$ ) to measure technical efficiency; also to measure operational effectiveness total number of passengers transported in a year is used as an output variable.

Then, the study employed a CCR-DEA input-orientation model by cross-sectional data to evaluate the enterprise's efficiency. It is because input orientation is assumed that the inputs in an organization are controllable compared to outputs. Enterprise can control its resources used in providing transit services (number of buses, number of employees, etc.); but cannot manage the number of passengers transported on their services.

Last, DEAP 2.1 software was used to compute all operators' efficiency scores based on the CCR inputoriented model. The following figure shows the flow technique of DEA-CCR efficiency analysis and slack variables investigation for the study. 


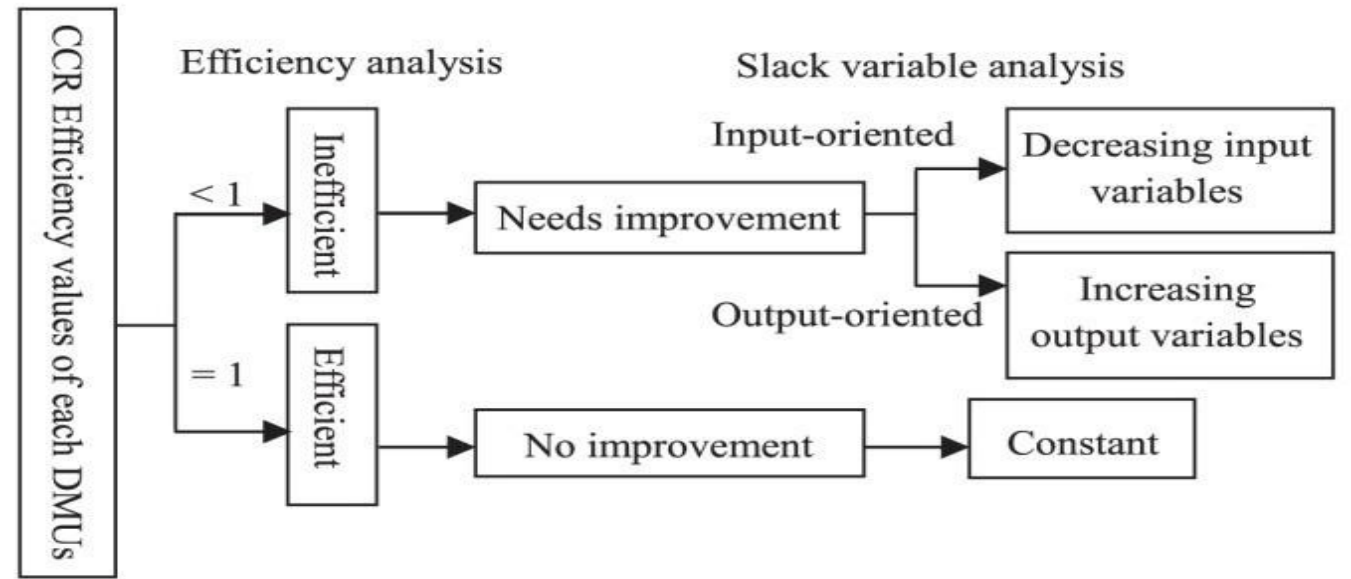

Figure 3. The flow of DEA-CCR model and Slack Variables Investigation

Hence, as can be seen in the above figure, concerning the efficiency value analysis of DMUs, when the efficiency score of the enterprise is less than one, it indicates the enterprise is technically inefficient, besides the inference is that the operating input to yield the output being used is not appropriate. Therefore, it should be an obligatory to decline input or enhance output reliant on the nature of the orientation model used. Thus, slack variable investigation can be used for inefficient DMU to display and advance the significant causes of inefficiency. The analysis will also categorize the use rate of variables (input and output), by evaluating how to increase the operational efficiency of inefficient DMUs by showing how much output to increase and/or how much input to decline, then building the inefficient DMU efficient (Almawsheki \& Shah, 2015).

\section{Results and Discussion}

This section of the study presents the outcomes of technical efficiency and operational effectiveness of public bus transport enterprise in the city. Cross-sectional data for 2016/17 and 2017/18 were used and applying DEACCR with an input-orientation model.

\subsection{Analysis of Technical Efficiency}

Figure 4, illustrates the result for technical efficiency of public bus transit providers in the city during 2016/17 and 2017/18. Thus, it can be observed, the technical efficiency score for Anbessa and Sheger city buses was equal to one in $2016 / 17$. This displays that they were technically efficient in utilizing their inputs (i.e. vehicles and staff) to offer the defined output (covered $\mathrm{km}$ ) as related to their peer operators. The score for Alliance (0.751) and PSETSE (0.344) indicates that they were technically inefficient in providing service in the city. The mean result for 2016/17 indicates 0.774 ; it implies that the aggregate public bus transport service during the year was technically inefficient in the city.

Moreover, the result for 2017/18 shows, only the Sheger city bus was technically efficient, and the result for others is less than one it shows that they were technically inefficient. Besides, the result shows, except for the Sheger city bus, the result of efficiency for all operators in the city was declined and the mean result was reached 0.612 and reduced by $79 \%$ during this year in the city.

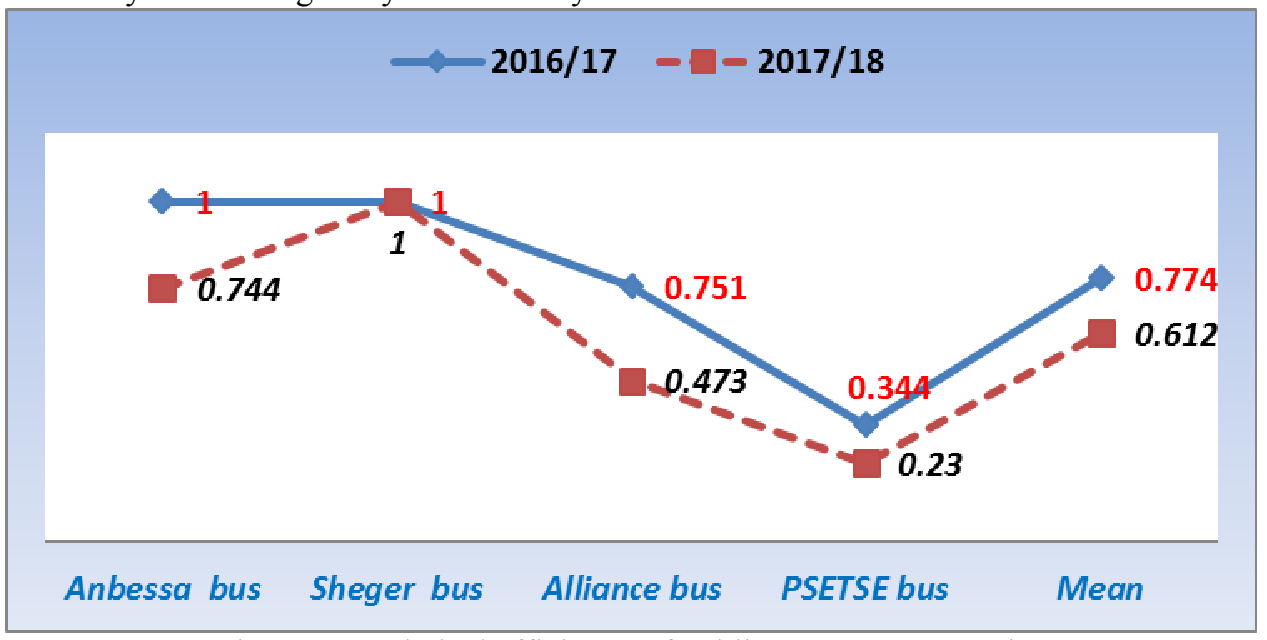

Figure 4. Technical efficiency of public transport enterprise 
On top of that, slack variable analysis suggests that inefficient DMUs should improve their input variables to enhance their technical efficiency and become efficient. This is possible by either increasing or decreasing the input levels. Thus, based on 2016/17, slack variable analysis suggests that Alliance city bus needs to improve its technical efficiency by $24.9 \%$ and PSETSE by $65.6 \%$ to become technically efficient. So, Figure 5 shows the percentage changes in each transit operator's improvement to become efficient in the years.

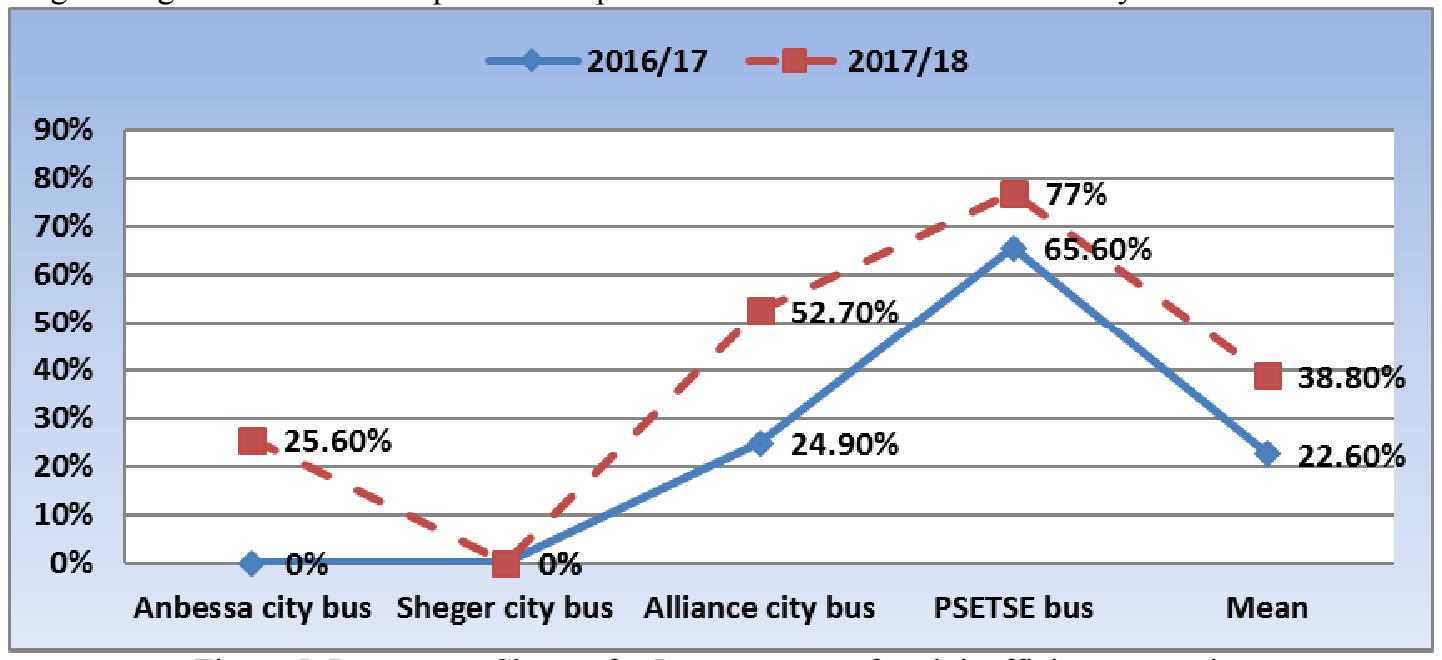

Figure 5. Percentage Change for Improvement of each inefficient enterprise

\subsection{Analysis of Operational Effectiveness}

Similarly, figure 6 illustrates the operational effectiveness results for each transit operator using the same input but with different outputs (i.e. the number of passengers per year). Thus, the effectiveness score only for the Anbessa city bus is equal to 1 during the two different years; and it implies that Anbessa is operationally effective in the city. The Sheger city bus was also scored one in 2017/18, and it was an operationally effective operator in the city. However, Alliance city bus and PSETSE were operationally ineffective for both years compared to other operators in the city in utilizing their inputs to produce desired outputs. Moreover, the mean result shows the city's public transport sector was operationally ineffective in the city for both years.

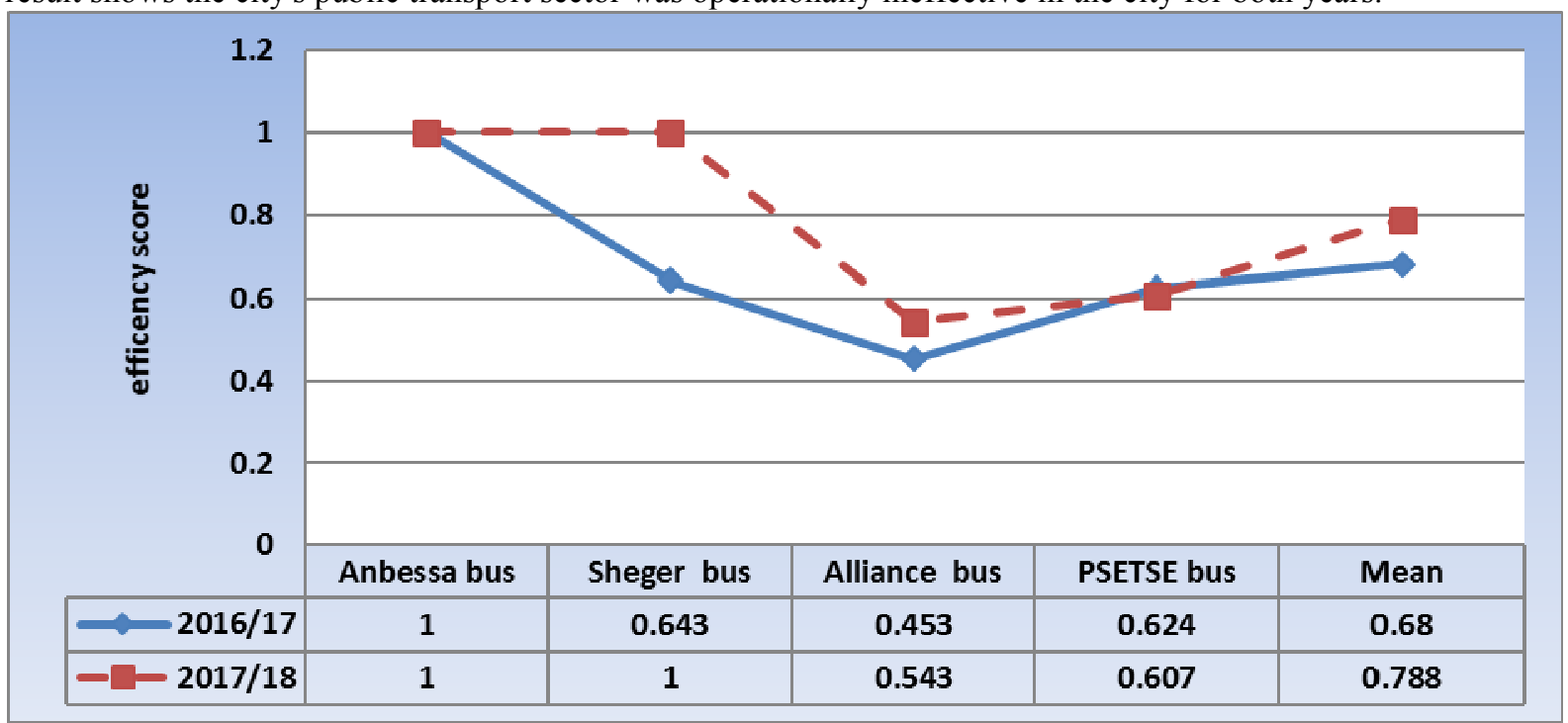

Figure 6. The operational effectiveness of public transport enterprise

Lastly, based on the above results, this study suggests the inefficient and ineffective transit enterprise should improve their performance. Thus, slack variable analysis has been annexed for them to become efficient transit agencies in the city.

\section{Conclusion}

This study evaluates the public bus transport sector's technical efficiency and operational effectiveness using the DEA approach for the first time in the city. Findings of the study indicate that Anbessa city bus and Shegr city bus were technically efficient in 2016/17, while Alliance city bus and PSETSE were inefficient in public transport operation in Addis Ababa city. Besides, in 2017/18, Sheger city bus was the only technically efficient 
transit service operator. The others Anbessa bus, PSETSE, and Alliance city bus were inefficient. Moreover, the mean result for both years shows public transport systems of the city was technically inefficient with the outcome of 0.774 and 0.612 in 2016/17 and 2017/18, respectively.

On the other hand, operational effectiveness shows only the Anbessa city bus was effective for both years in the city. Also, the effectiveness result for Sheger city bus has improved and became effective in 2017/18. The result for other transit service operators shows that they were ineffective, and they need to improve their efficiency level based on the outcome for slack analysis.

To sum up, Anbessa and Sheger city bus performs better than Alliance city bus and PSETSE bus. It indicates that Alliance and PSETSE are utilized their resources inefficiently to produce the desired output and are consumed ineffectively by the users. Hence, they need significant improvements in using their resources to produce the desired outcome, enhance their performance, and deliver services incompetent with other city operators.

Hence, the Government should encourage privately owned public bus transit operators in the city and provide subsidies and other incentives to all bus transit operators based on their current performance to promote the enterprise and enhance its operational efficiency.

\subsection{Implications of the study}

This study has significant implications both for practitioners and academics. From the management perspective, this study's results may provide managers and decision-makers to know the performance level of the enterprise in the city. It supports them to identify the inefficient DMUs and source of the enterprise's inefficiency; based on the result of slack variable analysis, they can change the inefficient organization to efficient. Moreover, they can measure the efficiency level of depots, routes, branches using the DEA approach to identify the efficient and inefficient DMUs and improve based on the result of DEA.

From the research perspective, this study addresses a research gap by using DEA in the city's public transport sector. DEA can be used in research on various sectors of the country (e.g. hospitals, banks, schools, etc.) by applying similar procedures to know their performance level in the provision of service for the community and identify the inefficient DMUs for policy insight development to improve the services, especially in developing countries.

\section{Acknowledgments}

This paper is extracted from the Ph.D. thesis of the corresponding author titled "A Study on Evaluating the Performance of Mass Transit Service in Addis Ababa, Ethiopia" which will be submitted in partial fulfillment of the requirement for the degree of Ph.D. in Urban and Regional Planning. Addis Ababa University, Ethiopia.

\section{Declaration of Conflicting Interests}

The author(s) declared no potential conflicts of interest with respect to the research, authorship, and/or publication of this article.

\section{Funding}

The author(s) received no financial support for the research, authorship, and/or publication of this article.

\section{References}

Abreha, D. A. (2007). Analyzing Public Transport Performance Using Efficiency Measures and Spatial Analysis; the case of Addis Ababa, Ethiopia. International Institute for Geo-Information Science and Earth Observation, the Netherlands.

Addis Ababa Transport Authority (2017). A Study on Allocation of Subsidy for Public Transport Agencies in Addis Ababa.Ethiopia

Agarwal, S. (2016). Measuring the Efficiency of Public Transport Sector in India: An Application of Data Envelopment Analysis. https://doi.org/10.21648/arthavij/2009/v51/i2/115392

Alan Armstrong-Wright and Sebastien Thiriez. (1987). Bus Services: Reducing Costs, Raising Standards. Retrieved from http://www.timesofmalta.com/articles/view/20040718/letters/busservices.117521\#.Ut0wyhBFB61

Almawsheki, E. S., \& Shah, M. Z. (2015). Technical Efficiency Analysis of Container Terminals in the Middle Eastern Region. Asian Journal of Shipping and Logistics, 31(4), 477-486. https://doi.org/10.1016/j.ajsl.2016.01.006

Ashish Verma, and T.V. Ramanayya. (2014). Public Transport Planning and Management in Developing Countries. CRC press.

Ayadi, A. (2013). The Evaluation of the Effectiveness and Efficiency of the Public Transport System in Tunisia. Application of DEA. Valahian Journal of Economic Studies, 4(1), 7. 
Azadeh, A., Salehi, V., \& Kianpour, M. (2018). Performance evaluation of rail transportation systems by considering resilience engineering factors: Tehran railway electrification system. Transportation Letters, 10(1), 12-25. https://doi.org/10.1080/19427867.2016.1207928

Banker, R. D., Charnes, A., \& Cooper, W. W. (1984). Some models for estimating technical and scale inefficiencies in data envelopment analysis. Management Science, 30(9), 1078-1092. http://dx.doi.org/10.1287/mnsc.30.9.1078

Barnum, D. T., McNeil, S., \& Jonathon, H. (2007). Comparing the Efficiency of Public Transportation Subunits Using Data Envelopment Analysis. Journal of Public Transportation, 10(2). http://dx.doi.org/10.5038/23750901.10.2.1

Berhan, E. (2013). Performance Analysis and Route Design of Addis Ababa Public Bus Transport.

Berhan, E., Beshah, B., \& Kitaw, D. (2013). Performance Analysis on Public Bus Transport of the City of Addis Ababa. International Journal of Computer Information Systems and Industrial Management Applications, 5, 2150-7988. Retrieved from www.mirlabs.net/ijcisim/index.html

Boru, T. (2014). Efficiency in the Ethiopian Banking System: An Application of Data Envelopment Analysis. European Journal of Business and Managemen, 6(23), 129-138.

Carotenuto, P., Coffari, A., Gastaldi, M., \& Levialdi, N. (2017). Analyzing Transportation Public Agencies Performance Using Data Envelopment Analysis. IFAC Proceedings Volumes, 30(8), 655-660. https://doi.org/10.1016/s1474-6670(17)43895-x

Charnes, A., Cooper, W. W., \& Rhodes, E. (1978). Measuring the efficiency of decision-making units. European Journal of Operational Research 2, 429-444. http://dx.doi.org/10.1016/0377-2217(78)90138-8

Chiou, Y. C., Lan, L. W., \& Yen, B. T. H. (2010). A joint measurement of efficiency and effectiveness for nonstorable commodities: Integrated data envelopment analysis approaches. European Journal of Operational Research, 201(2), 477-489. https://doi.org/10.1016/j.ejor.2009.03.005

Coelli, Tim. 1996a. "A guide to DEAP Version2.1.: A Data Envelopment Analysis (computer) program.” Cepa working paper, 96/08, Department of Econometrics, University of New England, Australia:1-49

Cooper, W. W., Seiford, L. M., \& Zhu, J. (2011). Handbook on Data Envelopment Analysis(Vol. 164). International Series of Operations Research \& Management Science, Springer Science \& Business Media. http://dx.doi.org/ 10.1007/978-1-4419-6151-8_ 11

Dagnaw D. \& Wang, M. (2018). Drivers of Téchnical Efficiency of Ethiopian Commercial Banks: DEA Approach \& Tobit Model. Research Journal of Finance and Accounting, 9(4), 30-38. Retrieved from www.iiste.org

Dajani, J. S., \& Gilbert, G. (1978). Measuring the performance of transit systems. Transportation Planning and Technology, 4(2), 97-103. https://doi.org/10.1080/03081067808717125

Daven Carter and Timothy J. Lomax (1992). Development and application of performance measures for rural public transportation operators. Transportation Research Record, (1338), 28-36.

Dhingra, C. (2011). Measuring Public Transport Performance: Lessons for Developing Cities. Sustainable Urban Transport Technical Document, 9. https://doi.org/10.1017/CB09781107415324.004

Dyson, R.G., Allen, R., Camanho, A.S., Podinvshi, V.V., Sarrico, C.S. and Shale, E.A.(2001)," Pitfalls and protocols in DEA". European Journal of Operational Research,38:245-259

Eboli, L., \& Mazzulla, G. (2012). Performance indicators for an objective measure of public transport service quality. European Transport - Trasporti Europei, (51), 1-21.

Estrada, M., Salanova, J. M., Medina-Tapia, M., \& Robusté, F. (2020). Operational cost and user performance analysis of on-demand bus and taxi systems. Transportation Letters, 00(00), 1-14. https://doi.org/10.1080/19427867.2020.1861507

Fielding, G. J., Babitsky, T. T., \& Brenner, M. E. (1985). Performance evaluation for bus transit. Transportation Research Part A: General, 19(1), 73-82. https://doi.org/10.1016/0191-2607(85)90009-3

Garamu, G. (2016). Technical Efficiency and Productivity of Ethiopian Commercial Banks: Data Envelopment Analysis (DEA) Approach. International Journal of Scientific and Research Publications, 6(9), 860. Retrieved from www.ijsrp.org

Gebeyehu, M. and, \& Takano, S. (2007a). Diagnostic Evaluation of Public Transportation Mode Choice in Addis Ababa. Journal of Public Transportation, Vol. 10(4). https://doi.org/10.1021/ic50162a028

Gebeyehu, M. and, \& Takano, S. (2007b). EVALUATION OF BUS ROUTES PERFORMANCE IN THE CITY OF ADDIS ABABA USING STOCHASTIC FRONTIER MODEL. INFRASTRUCTURE PLANNING REVIEW, 24(3), 447-457. https://doi.org/10.2208/journalip.24.447

Greene, D. L., \& Wegener, M. (1997). Sustainable transport. Journal of Transport Geography, 5(3), 177-190.

Hafezi, M. H., Shokri, F., \& Falamarzi, A. (2013). A Novel Method for Travel System Patterns. International Journal of Transportation Engineering, 1(2), 93-100.

Han, J., and Y. Hayash. 2008. "A Data Envelopment Analysis for Evaluating the Perfor $\neg$ mance of China's Urban Public Transport Systems.” International Journal of Urban Sciences, 12 (2):173- 183. 
Henning, T., Essakali, M. D., \& Oh, J. E. (2011). A Framework for Urban Transport Benchmarking. International Bank for Reconstruction and Development / The World Bank., 78.

Hwe, S. K., Cheung, R. K., \& Wan, Y. wah. (2006). Merging bus routes in Hong Kong's central business district: Analysis and models. Transportation Research Part A: Policy and Practice, 40(10), 918-935. https://doi.org/10.1016/j.tra.2006.03.005

Iles, R. (2005). Public Transport in Developing Countries. https://doi.org/10.1186/cc13998

Kral, P., \& Rohácová, V. (2013). Measuring the Efficiency of Public Road Transport Companies in the Slovak Republic USING DEA and SFA.

Lao, Y., \& Liu, L. (2009). Performance evaluation of bus lines with data envelopment analysis and geographic information systems. Computers, Environment and Urban Systems, 33(4), 247-255.

Mihretie, M. (2013). Urban Public Bus Transport Service Quality in the City of Addis Ababa Case Study: Anbessa City Bus Enterprise (ACBE). Addis Ababa University. Retrieved from http://files/48/Mihretie Urban Public Bus Transport Service Quality in the .pdf

Murray, A. T., Davis, R., Stimson, R. J., \& Ferreira, L. (1998). Public transportation access. Transportation Research Part D: Transport and Environment, 3(5), 319-328. https://doi.org/10.1016/S13619209(98)00010-8

Mutyasira, V. (2017). PROSPECTS FOR SUSTAINABLE INTENSIFICATION OF SMALLHOLDER FARMING SYSTEMS IN ETHIOPIAN HIGHLANDS. Colorado State University-Fort Collins, Colorado.

Norouzian-Maleki, P., Izadbakhsh, H., Saberi, M., Hussain, O., Jahangoshai Rezaee, M., \& GhanbarTehrani, N. (2020). An integrated approach to system dynamics and data envelopment analysis for determining efficient policies and forecasting travel demand in an urban transport system. Transportation Letters, 00(00), 1-17. https://doi.org/10.1080/19427867.2020.1839716

Rahul Raoniar, Amudapuram Mohan Rao, S. Velmurugan. (2015). Public Transport Performance Evaluation Techniques -A Review. Research Gate, 1-10.

Seid, A. K. (2006). Technical efficiency of selected hospitals in Addis Ababa: data envelopment analysis approach.

Thomas J. Cook and Lawrie, J. J. (2004). USE OF PERFORMANCE STANDARDS AND MEASURES FOR PUBLIC TRANSPORTATION SYSTEMS. Transportation Research.

Todd Litman(2005).Well measured- Developing Indicators for Comprehensive and Sustainable Transport Planning. Transport Research Board/TRB/.

Transportation Research Board. (2002). TCRP Report G-6: A Guidebook for Developing a Transit PerformanceMeasurement System.

Vuchic, V., R.(2005). Urban Transit: Operations, planning, and economics. New Jersey: John Wiley and Sons Inc.

Zenebe Lema, T. (2017). Determinants of bank technical efficiency: Evidence from commercial banks in Ethiopia. Cogent Business and Management, 4(1). https://doi.org/10.1080/23311975.2016.1268356

Annex 1. Descriptive Statistics of the Variables 2016/17 and 2017/18

\begin{tabular}{|l|l|l|l|l|l|l|l|l|}
\hline \multirow{2}{*}{} & \multicolumn{3}{|c|}{ Input variables } & \multicolumn{4}{c|}{$\begin{array}{c}\text { Output variables } \\
\text { \# of Operated buses }\end{array}$} & \multicolumn{2}{c|}{$\begin{array}{c}\text { \# of Employees } \\
\text { Vehicle-km passengers } \\
\text { (for efficiency measure) }\end{array}$} \\
\cline { 2 - 10 } & $2016 / 17$ & $2017 / 18$ & $2016 / 17$ & $2017 / 18$ & $2016 / 17$ & $2017 / 18$ & $2016 / 17$ & $2017 / 18$ \\
\hline Max & 447 & 438 & 3398 & 3559 & $133,770,900$ & $105,758,047$ & $18,759,848$ & $16,220,017$ \\
\hline Min & 70 & 80 & 333 & 339 & $8,064,000$ & $6,763,518$ & 644,965 & 653,622 \\
\hline Average & 217.333333 & 230 & 1449.33333 & 1455.5 & $51,942,436$ & $42,322,041$ & $7,520,084$ & $7,771,630$ \\
\hline SD & 170.008578 & 155.3984 & 1450.3235 & 1496.682 & 61125633.32 & 46659006.3 & 8367299.89 & 7769753.6 \\
\hline
\end{tabular}

Annex - 2 Slack Variable Analysis: Suggestion for improvement of inefficient enterprises

i. Technical efficiency result

Year: $2016 / 17$

\begin{tabular}{|lllll|}
\hline $\begin{array}{l}\text { DMU } \\
\text { Alliance city bus } \\
\text { (Te: 0.751) }\end{array}$ & Output 1 & 1910880 & Output 1 & \multicolumn{1}{c|}{ Projected value } \\
\cline { 2 - 5 } & Input 1 & 70 & Input 1 & 52 \\
\cline { 2 - 5 } & Input 2 & 452 & Input 2 & 339 \\
\hline $\begin{array}{l}\text { PSETSE } \\
\text { (Te: } 0.344)\end{array}$ & Output 1 & 644965 & Output 1 & 644965 \\
\cline { 2 - 5 } & Input 1 & 149 & Input 1 & 17 \\
\cline { 2 - 5 } & Input 2 & 333 & Input 2 & 114 \\
\hline
\end{tabular}

Note: Anbessa and Sheger bus are efficient 
Year: $2017 / 18$

\begin{tabular}{|c|c|c|c|c|}
\hline DMU & & al value & & d value \\
\hline Anbessa city bus & Output 1 & 16220017 & Output 1 & 16220017 \\
\hline (Te:0.744) & Input 1 & 438 & Input 1 & 325 \\
\hline & Input 2 & 3559 & Input 2 & 1936 \\
\hline Alliance city bus & Output 1 & 1712880 & Output 1 & 1712880 \\
\hline (Te: 0.473 ) & Input 1 & 80 & Input 1 & 34 \\
\hline & Input 2 & 432 & Input 2 & 204 \\
\hline PSETSE & Output 1 & 653622 & Output 1 & 653622 \\
\hline (Te:0.230) & Input 1 & 151 & Input 1 & 13 \\
\hline & Input 2 & 339 & Input 2 & 78 \\
\hline
\end{tabular}

Note: Sheger bus is efficient

ii. Operational effectiveness result

Year: $2016 / 17$

\begin{tabular}{|c|c|c|c|c|}
\hline \multirow{4}{*}{$\begin{array}{l}\text { DMU } \\
\text { Sheger city bus } \\
\text { (e: } 0.643)\end{array}$} & \multicolumn{2}{|c|}{ Original value } & \multicolumn{2}{|c|}{ Projected value } \\
\hline & Output 1 & 19800000 & Output 1 & 19800000 \\
\hline & Input 1 & 121 & Input 1 & 66 \\
\hline & Input 2 & 782 & Input 2 & 502 \\
\hline \multirow{3}{*}{$\begin{array}{l}\text { Alliance city bus } \\
\text { (e: } 0.453)\end{array}$} & Output 1 & 8064000 & Output 1 & 8064000 \\
\hline & Input 1 & 70 & Input 1 & 26 \\
\hline & Input 2 & 452 & Input 2 & 204 \\
\hline \multirow{3}{*}{$\begin{array}{l}\text { PSETSE } \\
(e: 0.624)\end{array}$} & Output 1 & 8184814 & Output 1 & 8184814 \\
\hline & Input 1 & 149 & Input 1 & 27 \\
\hline & Input 2 & 333 & Input 2 & 207 \\
\hline
\end{tabular}

Note: Anbessa is efficient

Year: 2017/18

\begin{tabular}{|lllll|}
\hline DMU & \multicolumn{3}{c|}{ Original value } & \multicolumn{2}{c|}{ Projected value } \\
(e:0.543) & Output 1 & 7718400 & Output 1 & 7718400 \\
\cline { 2 - 5 } & Input 1 & $\mathbf{8 0}$ & Input 1 & 39 \\
\cline { 2 - 5 } $\begin{array}{l}\text { Input 2 } \\
\text { (e: } 0.607)\end{array}$ & Output 1 & 432 & Input 2 & 234 \\
\cline { 2 - 5 } & Input 1 & $\mathbf{6 7 6 3 5 1 8}$ & Ontput 1 & 6763518 \\
\cline { 2 - 5 } & Input 2 & 339 & Input 2 & 34 \\
\hline
\end{tabular}

Note : Anbessa and Shger are efficient

Note i. Input 1: \# of buses

Input 2: \# of employees

For analysis of operational effectiveness output 1 is the number of people transported per year.

For analysis of technical efficiency output 1 is the total vehicle-covered $\mathrm{km}$ per year.

Projected value is a value for improvement to enhance their efficiency score

Note ii. Government Fiscal Year (FY) in Ethiopia: July 8- July 7

Ethiopian Fiscal year (EFY) Gregorian (European Year Equivalent)

2009 E.C

Gregorian $2016 / 2017$

2010 E.C. 